\title{
The influence of ternary and quaternary alloy additions on the superelastic behaviour of metastable Ti-Nb based alloys
}

\author{
N. G. Jones ${ }^{\mathrm{a}^{*}}$, E. M. Hildyard ${ }^{\mathrm{a}}$, L. D. Connor ${ }^{\mathrm{b}}$ \\ ${ }^{a}$ University of Cambridge, Cambridge, UK \\ ${ }^{\mathrm{b}}$ Diamond Light Source Ltd, Didcott, UK \\ "ngj22@cam.ac.uk
}

\begin{abstract}
$\underline{\text { Abstract }}$
The superelastic behaviour of $\mathrm{Ti}-\mathrm{Nb}$ alloys gives rise to properties that are attractive for specific applications in the biomedical and aerospace sectors. However, to date, industrial utilisation of these alloys has been limited due the inability to tailor the transformation conditions or achieve stable cyclic behaviour. Alloying is the primary method for modifying transformation conditions but significant variations exist between the results of different studies within the literature. Here, to try and provide increased clarity, the transformation behaviour of Ti-24Nb-(0-8)Ta and $\mathrm{Zr}$ (at.\%) have been investigated using in situ synchrotron diffraction to directly assess the transformation behaviour of the alloys in response to both temperature and tensile loads. In contrast to previous reports, no evidence of the $\alpha$ " phase was found in any of the alloys when cooled from 350 to $-196^{\circ} \mathrm{C}$. In addition, the $\beta$ to $\alpha^{\prime \prime}$ transformation was observed to be reversible when loaded at both $30^{\circ} \mathrm{C}$ and $-196^{\circ} \mathrm{C}$. These observations suggest that $\beta$ stability may be far greater than previously thought and requires a review of the current mechanistic understanding.
\end{abstract}

\section{Introduction}

Metastable $\beta$ Ti alloys, based on the Ti-Nb system, have been the subject of considerable research over the past fifteen years due to their susceptibility to undergo the reversible $\beta$ to $\alpha$ " transformation. Depending upon the composition of the alloy and the conditions under which it is loaded, this martensitic transformation can give rise to superelastic or shape memory behaviour [1, 2]. These properties, in combination with low $\beta$ phase elastic moduli, make these alloys attractive for a number of potential applications across the biomedical and aerospace engineering sectors. However, the uptake of these materials, particularly in the aerospace sector is being limited by a number of as yet unresolved technical limitations. Examples of these limitations include, an inability to tailor the transformation behaviour to a specific application operating conditions, the difficulty of controlling the formation and evolution of the $\omega$ phase and the progressive change in behaviour that occurs with repeated transformation cycling $[3,4]$.

Modification of the transformation conditions and associated behaviour is generally achieved through the incorporation of additional elements into an alloy. However, despite their technological importance, there are relatively few systematic studies that fully characterise the role of different alloying elements on the Ti-Nb system. Additions of bio-compatible elements, such as Ta and Zr, have been the most widely studied and it is generally agreed that these elements stabilise the $\beta$ phase and suppress the martensitic transformation. However, significant discrepancies exists as to the extent to which Zr additions depress the martensitic start temperature, with several values reported within the range of -30 to $-65{ }^{\circ} \mathrm{C}$ per at. $\%[1,5,6]$. Fewer studies have considered the influence of Ta additions but these are reported to suppress the martensite start temperature by $\sim 30^{\circ} \mathrm{C}$ per at.\% $[1,7]$. There is also significant disagreement within the literature with respect to the influence that these additions may have on the $\omega$ phase. In the case of $\mathrm{Zr}$, it has been reported that additions of this element can supress [8,9], promote [10] and have no effect [11, 12] upon the $\omega$ phase. Such discrepancies are not conducive for successful engineering design.

The underlying reasons for the variations between different studies are rarely discussed but several factors could contribute. These include; the suitability and sensitivity of the measurement technique used to characterise the transformation behaviour; variations in the actual composition of materials characterised and, in particular, the interstitial content; and differences in the process history and initial microstructural condition, which will influence any subsequent behaviour. Without this information, understanding and rationalising the reported variations is extremely difficult.

Consequently, in this manuscript, we report on part of a holistic experimental study that explores the effect of different alloying elements on the transformation behaviour of the Ti-Nb based system. Two series of alloys $\mathrm{Ti}-24 \mathrm{Nb}-(2-8) \mathrm{Ta}$ and $\mathrm{Ti}-24 \mathrm{Nb}-(2-8) \mathrm{Zr}$ (at.\%) have been investigated using in situ synchrotron diffraction to directly assess the transformation behaviour of the alloys in response to both temperature and tensile loads.

\section{Experimental Methods}

Eight ingots, with nominal composition of Ti-24Nb-(2,4,6,8)X (at.\%) where $\mathrm{X}$ was either Ta or $\mathrm{Zr}$, were produced by arc melting pure elemental metals under an inert atmosphere. To ensure the best possible macroscopic homogeneity, each ingot was inverted and remelted a total of five times. Transverse sections, approximately $6 \mathrm{~mm}$ in height, were cut from the as-cast bar and cold rolled to strip form, with a total reduction in thickness of about $90 \%$. Compositional analysis of the metallic content of the alloys was performed using inductively coupled plasma optical emission spectroscopy, whilst the oxygen concentration was determined using an inert gas fusion method.

Small scale tensile specimens, with an $\sim 0.25 \mathrm{~mm}^{2}$ square cross section and a $14 \mathrm{~mm}$ gauge length, were removed from the cold rolled strips using electro discharge machining. The tensile axis of the specimens were aligned to the rolling direction of the strips. The specimens were solution heat treated at $900^{\circ} \mathrm{C}$ for 5 minutes followed by water quenching whilst encapsulated in quartz ampoules under vacuum. It should be noted that in order to avoid surface oxidation during the quench the ampoules were not broken, consistent with previous work [13].

(C) The Authors, published by EDP Sciences. This is an open access article distributed under the terms of the Creative Commons Attribution License 4.0 (http://creativecommons.org/licenses/by/4.0/). 
The evolution of the microstructure as a function of both temperature and applied load were studied in situ using synchrotron X-ray diffraction on the I12 beamline at Diamond Light Source. The beamline was configured in transmission Debye-Scherrer geometry and used a $500 \times 500 \mu \mathrm{m}$ incident beam with a wavelength of $0.15527 \AA$. Two dimensional diffraction patterns were collected every 4 seconds using a Thales Pixium area detector located $\sim 1142 \mathrm{~mm}$ from the sample. Specimens were heated and cooled at a rate of $30^{\circ} \mathrm{Cmin}^{-1}$ and loaded at an initial strain rate of approximately $1 \times 10^{-4} \mathrm{~s}^{-1}$ using a Linkam TST350 stage. In all cases, samples were heated to $350^{\circ} \mathrm{C}$ prior to being cooled to a testing temperature between 30 and $-196^{\circ} \mathrm{C}$, where the specimen was loaded to just past macroscopic yielding or a maximum load of $\sim 190 \mathrm{~N}$. The resulting diffraction data was spatially corrected and azimuthally integrated using the Fit $2 \mathrm{D}$ programme [14].

\section{$\underline{\text { Results }}$}

The experimentally determined composition of the alloys used in this study are given in Table 1 . All were found to be very close to the nominal compositions, with a maximum elemental variation of 0.6 at. $\%$. In addition, the concentration of oxygen in the alloys was also found to be very consistent across the series, meaning any systematic variations in behaviour will be related to the difference in the Ta or $\mathrm{Zr}$ content of the alloys.

Table 1: Measured compositions of the alloys produced for this study (at.\%)

\begin{tabular}{|c|c|c|c|c|c|}
\hline Alloy & $\mathrm{Ti}$ & Nb & Ta & $\mathbf{Z r}$ & o \\
\hline Ti-24Nb-2Ta & bal. & 24.4 & 2.0 & - & 0.3 \\
\hline Ti-24Nb-4Ta & bal. & 24.3 & 4.0 & - & 0.2 \\
\hline Ti-24Nb-6Ta & bal. & 24.3 & 5.8 & - & 0.2 \\
\hline Ti-24Nb-8Ta & bal. & 23.8 & 7.4 & - & 0.2 \\
\hline Ti-24Nb-2Zr & bal. & 24.4 & - & 2.0 & 0.3 \\
\hline $\mathrm{Ti}-24 \mathrm{Nb}-4 \mathrm{Zr}$ & bal. & 24.5 & - & 4.1 & 0.3 \\
\hline Ti-24Nb-6Zr & bal. & 24.6 & - & 6.0 & 0.3 \\
\hline Ti-24Nb-8Zr & bal. & 24.5 & - & 8.3 & 0.3 \\
\hline
\end{tabular}

The influence of alloying content on the initial phase constitution of the materials following solution heat treatment and water quenching was assessed using the diffraction data shown in Figure 1. In all cases, the alloys were predominately $\beta$ phase, however, additional minority peaks could be seen in several patterns. Of particular importance within the patterns of the alloys with 2 at.\% Ta and $\mathrm{Zr}$, was the additional $(020)_{\alpha \text { " }}$ peak at $\sim 3.7^{\circ} 2 \theta$, which is just below the angle associated with the $\{110\}_{\beta}$ peak. A similarly located peak has been observed in the diffraction pattern of Ti-24Nb following identical processing and is known to be characteristic of the $\alpha^{\prime \prime}$ phase. A corresponding peak was not observed in any of the diffraction patterns belonging to alloys with greater concentrations of Ta or Zr. The additional peaks marked with an * in the elevated content alloys from both series are believed to be an artefact in the data, although the precise source of this signal has yet to be fully identified.

These results seem to suggest that both Ta and Zr suppress the formation of $\alpha$ " at room temperature, in good agreement with previous findings for similar alloy series [2, 7, 12]. However, it must be recognised that the initial condition of these alloys will be highly dependent upon the processing history and, in particular, the cooling rate experienced from the solution heat treatment [13, 15]. Whilst the procedure was reproduced closely as reasonably possible, small variations could lead to differences in the constituent phases and, as such, care should be taken when drawing conclusions about the relative stability of the $\beta$ and $\alpha^{\prime \prime}$ phase based solely these results. 

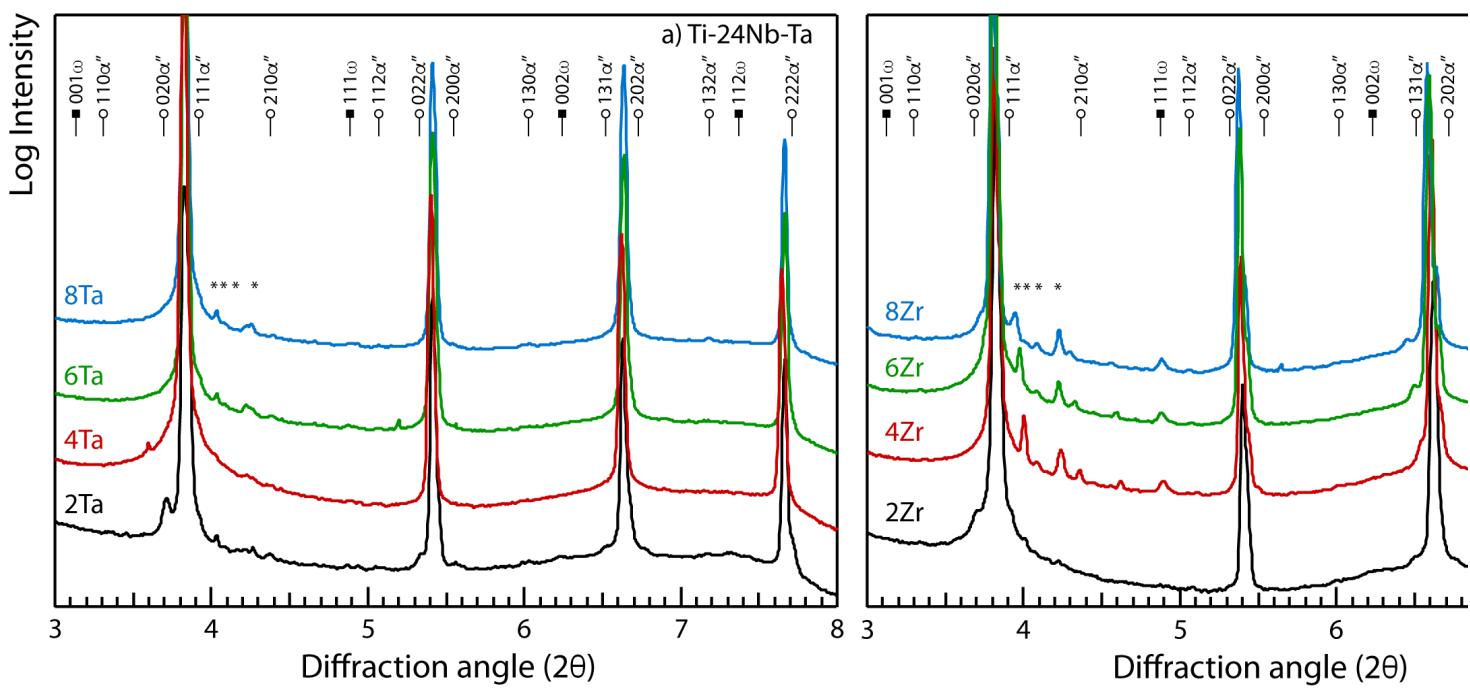

Figure 1: Synchrotron $\mathrm{X}$-ray diffraction patterns of the a) Ti-24Nb-Ta and b) Ti-24Nb-Zr alloys in the solution heat treated and water quenched condition.

To remove any variation between the samples due to slight differences in cooling rate, all of samples were heated in situ to $350^{\circ} \mathrm{C}$ prior to cooling to the testing temperature at a controlled rate of $30^{\circ} \mathrm{C}$ min ${ }^{-1}$. As such, it was intended that this data would provide direct evidence of the reversion of the $\alpha^{\prime \prime}$ to the parent $\beta$ phase during heating and, correspondingly, the onset temperature for the $\beta$ to $\alpha^{\prime \prime}$ during cooling. To demonstrate this, diffraction data from the two least stabilised alloys, Ti-24Nb-2Ta and Ti-24Nb-2Zr at key temperatures in a cycle to $-196^{\circ} \mathrm{C}$ are shown in Figure 2 . During heating to $350^{\circ} \mathrm{C}$, the peak at $\sim$ $3.7^{\circ} 2 \theta$ decreased in intensity and disappeared, as shown by its absence in the $350^{\circ} \mathrm{C}$ diffraction patterns shown in red in Figure 2. Analysis of all of the intermediate diffraction patterns enabled a direct determination of the thermal stability limit of the $\alpha^{\prime \prime}$ phase in these samples, which was found to be $\sim 186^{\circ} \mathrm{C}$ for Ti-24Nb-2Ta and $\sim 190^{\circ} \mathrm{C}$ for Ti-24Nb-2Zr. Heating the more heavily stabilised alloys to $350^{\circ} \mathrm{C}$ in an identical manner yielded no change in the diffraction patterns other than a change in the peak position consistent with thermal expansion. As such, at $350^{\circ} \mathrm{C}$ all of the alloys were $\beta$ phase, with no evidence for the presence of the $\alpha^{\prime \prime}$ martensite.

When the alloys were cooled from $350^{\circ} \mathrm{C}$ to $-196^{\circ} \mathrm{C}$ at a rate of $30^{\circ} \mathrm{C} \mathrm{min}^{-1}$, no evidence of the $\alpha^{\prime \prime}$ phase was detected in any of the studied materials. This result is highlighted by the corresponding diffraction patterns for Ti-24Nb-2Ta and Ti-24Nb-2Zr, which are shown in blue in Figure 2. As these are the least stabilised alloys considered in this study, they would be expected to have the highest martensite start temperatures in their respective series. Interpolating between previous datasets taken from the literature data suggested the martensitic start temperature for both alloys should be in the vicinity of $0^{\circ} \mathrm{C}[2,5,7]$. Therefore, the absence of any peaks characteristic of the $\alpha^{\prime \prime}$ phase in these alloys at $-196^{\circ} \mathrm{C}$ was very surprising and indicated that the transformation temperature had not yet been reached. However, upon cooling, several very broad peaks were observed to increase in intensity within the diffraction patterns of each sample. The peaks can be seen at diffraction of $\sim 3.1,4.9,6.3$ and $7.35^{\circ} 2 \theta$ and these positions are consistent with the $\omega$ phase. Consequently, the in situ data gathered here shows that the $\omega$ phase forms upon cooling to cryogenic temperatures rather than the $\alpha^{\prime \prime}$ phase. 

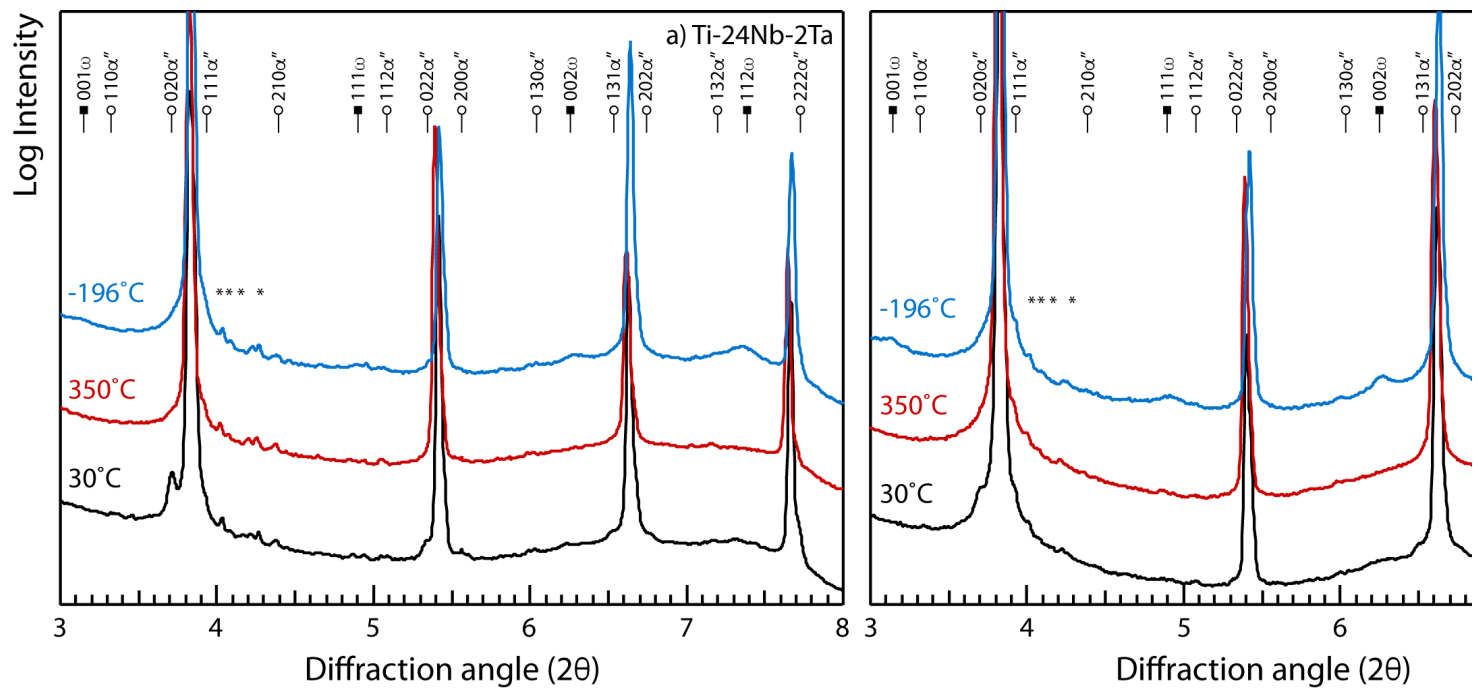

Figure 2: Synchrotron X-ray diffraction patterns from a) Ti-24Nb-2Ta and b) Ti-24Nb-2Zr when in the initial solution heat treated and water quenched condition (black), heated to $350^{\circ} \mathrm{C}\left(\right.$ red) and cooled to $-196^{\circ} \mathrm{C}$ (blue).

To study the response of these alloys to an applied load, tensile testing was performed at temperatures of $30^{\circ} \mathrm{C}$ and $-196^{\circ} \mathrm{C}$. During loading, additional peaks were observed within the diffraction patterns at locations consistent with the $\alpha^{\prime \prime}$ phase. An example of this behaviour is provided in Figure 3, which shows the microstructural evolution of Ti-24Nb-6Zr when subjected to an applied load at room temperature. Similar behaviour was observed in all of the alloys when mechanically loaded at both $30^{\circ} \mathrm{C}$ and $-196^{\circ} \mathrm{C}$, except Ti-24Nb- $8 \mathrm{Zr}$, which did not appear to transform. These results indicate that the $\beta$ to $\alpha^{\prime \prime}$ transformation can occur over much wider temperature ranges than reported previously. In addition, since the data presented in Figure 2 indicated that these alloys were above their martensite start temperatures, there is also the possibility that they might be able to exhibit superelastic behaviour over a broad range too.
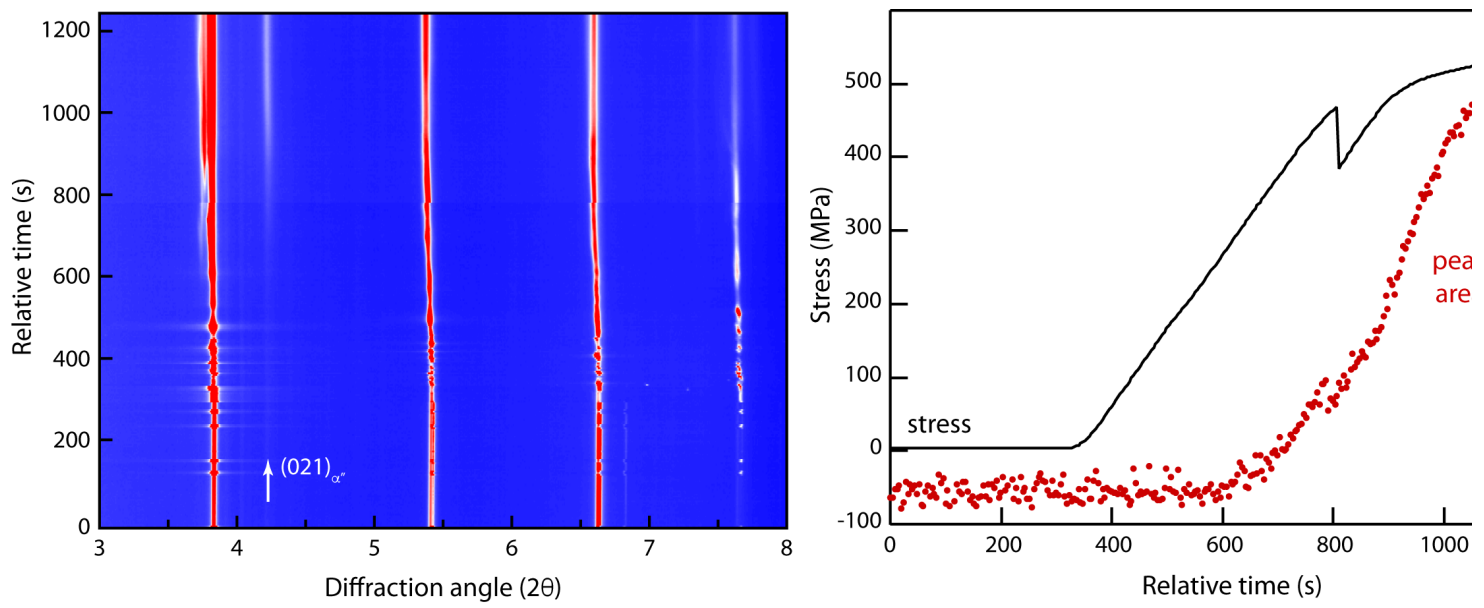

Figure 3: Microstructural evolution of Ti-24Nb-6Ta during room temperature loading: a) overview provided by an image plot of sequential diffraction patterns and b) the corresponding changes in fitted peak area of the $(021)_{a}$ " plotted alongside stress, both as a function of time. 
sample. Data corresponding to the loading and unloading of Ti-24Nb-8Ta when loaded to a peak stress of $\sim 520 \mathrm{MPa}$ at $30^{\circ} \mathrm{C}$ and $-196^{\circ} \mathrm{C}$ are shown in Figure 4 . The formation of the $\alpha "$ phase can clearly be seen during loading in both the sequential image plots and the fitted data corresponding to the $(021)_{\alpha}$. When the load is removed, the intensity of the $\alpha^{\prime \prime}$ reflections decreases, indicating the reversion of the $\alpha^{\prime \prime}$ phase at both temperatures, confirming the suggestion above that superelastic behaviour can also occur over very wide temperature ranges.
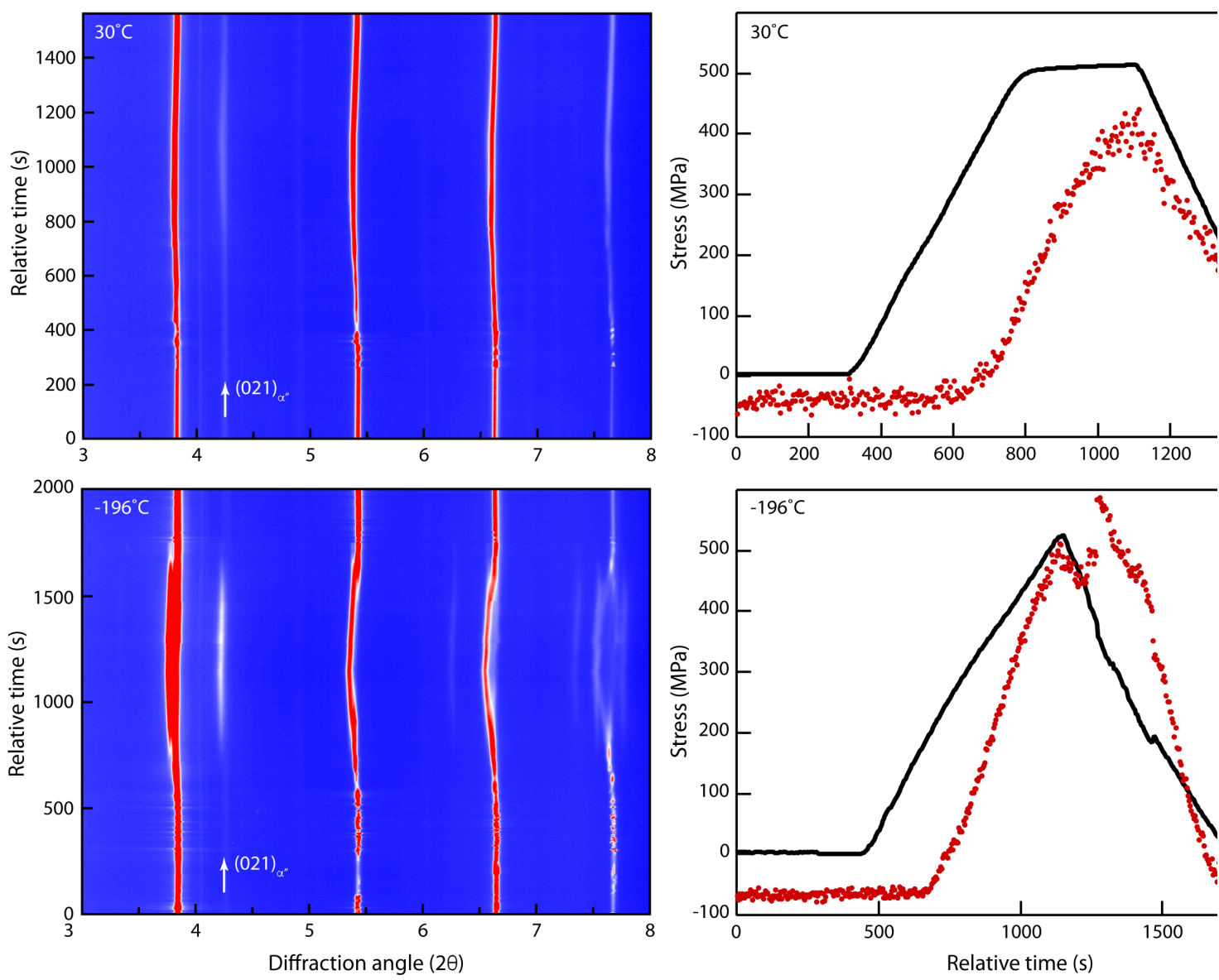

Figure 4: Sequential synchrotron X-ray diffraction patterns from Ti-24Nb-8Ta showing the evolution and reversion of the $\alpha^{\prime \prime}$ under the application and removal of an applied load at 30 and $-196^{\circ} \mathrm{C}$.

Discussion

The results presented here provide some new key insights into the behaviour of metastable Ti-Nb based alloys. The data obtained from the alloys in the initial condition, where the $\alpha$ " reflections were seen in the alloys with $2 \%$ additions, would commonly be interpreted to show that the martensite start temperature intersected room temperature at compositions intermediate to $2 \%$ and $4 \%$ Ta or Zr. However, when these samples were heated to $350^{\circ} \mathrm{C}$ and cooled, at a controlled rate, to $-196^{\circ} \mathrm{C}$, none of the alloys underwent a thermally driven transformation. As such, the true martensite start temperature for these alloys lies below $-196^{\circ} \mathrm{C}$ and, thus, the martensite observed in the initial condition must have formed in response to another stimulus, for example a quenching strain.

This suggestion is contrary to many reports in the literature $[2,5-7]$ but is further reinforced by the observation of superelastic behaviour at low temperatures. The reduction of the martensite peak area when the applied load is removed requires there to be a driving force for the reverse transformation. A driving force for reversion will only be present if the alloys are above their martensite start temperature and the $\beta$ phase is the thermodynamically stable phase. Consequently, it can be reasoned that in the absence of an applied load, the Gibbs energy curve of the $\beta$ phase has a lower energy than that of the $\alpha$ " phase. The application of a stress changes this situation and leads to the martensite becoming the thermodynamically favourable phase. 
not greatly affected by changes in temperature and are much more sensitive to applied stress. As such, the change in yield stress with temperature may well be a more critical feature, as this is an upper bound limit for fully recoverable superelastic behaviour. These observations are key to the potential use of these materials in engineering applications and in determining alloy design strategies.

In addition, the observed formation of the $\omega$ phase in all of the alloys when cooling to $-196^{\circ} \mathrm{C}$ is interesting, as it suggests that this phase is thermodynamically favourable at low temperature. However, the intensity of the corresponding diffraction peaks, and hence the volume fraction of this phase, were fairly low and so it is possible that the formation of $\omega$ phase is locally favourable only in certain parts of the material. These observations require further work but do indicate that neither $\mathrm{Zr}$ or Ta additions can fully suppress the $\omega$ phase.

\section{Conclusions}

In situ synchrotron diffraction has been used to study the transformation behaviour of a systematic series of alloys in the Ti-24Nb-(0-8)Ta and Ti-24Nb-(0-8)Zr (at.\%) system. Despite the presence of $\alpha$ " in the solution heat treated and quenched condition of the alloys containing $2 \% \mathrm{Ta}$ and $\mathrm{Zr}$, no evidence of $\alpha^{\prime \prime}$ phase formation was noted in any of the alloys when cooled from 350 to $-196^{\circ} \mathrm{C}$. The $\alpha$ " martensite was formed upon the application of an applied load in all alloys, except Ti-24Nb-8Zr, when loaded at $30^{\circ} \mathrm{C}$ and $-196^{\circ} \mathrm{C}$. In addition, evidence for superelastic behaviour, i.e. the reverse $\alpha^{\prime \prime}$ to $\beta$ transformation, was also observed at these conditions. Consequently, for the compositions studied, the $\beta$ phase must be more thermodynamically stable than the $\alpha^{\prime \prime}$ phase at temperatures between 30 and $-196^{\circ} \mathrm{C}$. The results also suggest that the difference between the Gibbs energy curves between the $\beta$ and $\alpha$ " phases is more strongly influenced by changes in stress than by changes in temperature.

\section{References}

1. S. Miyazaki, H.Y. Kim,H. Hosoda, Mater. Sci. Eng. A 438-440 (2006) 18-24

2. H.Y. Kim, Y. Ikehara, J.I. Kim, H. Hosoda,S. Miyazaki, Acta Mater. 54 (2006) 2419-2429

3. J. Coakley, K.M. Rahman, V.A. Vorontsov, M. Ohnuma,D. Dye, Mater. Sci. Eng. A 655 (2016) 399-407

4. V.A. Vorontsov, N.G. Jones, K.M. Rahman,D. Dye, Acta Mater. 88 (2015) 323-333

5. Y.L. Hao, S.J. Li, S.Y. Sun,R. Yang, Mater. Sci. Eng. A 441 (2006) 112-118

6. W. Ye, X. Mi,X. Song, Rare Metals 31 (2012) 227-230

7. H.Y. Kim, S. Hashimoto, J.I. Kim, T. Inamura, H. Hosoda,S. Miyazaki, Mater. Sci. Eng. A 417 (2006) 120-128

8. Q. Li, M. Niinomi, M. Nakai, Z. Cui, S. Zhu,X. Yang, Mater. Sci. Eng. A 536 (2012) 197-206

9. P.L. Ferrandini, F.F. Cardoso, S.A. Souza, C.R. Afonso,R. Caram, J. Alloy Compd. 433 (2007) 207-210

11. P.J.S. Buenconsejo, H.Y. Kim,S. Miyazaki, Acta Mater. 57 (2009) 2509-2515

12. E.L. Pang, E.J. Pickering, S.I. Baik, D.N. Seidman,N.G. Jones, Acta Mater. 153 (2018) 62-70

13. E. Pang, MPhil (2016) University of Cambridge

14. A.P. Hammersley, S.O. Svensson,A. Thompson, Nucl. Instrum. Methods 346 (1994) 312-321

15. D. Moffat, D. Larbalestier, Metall. Trans. A 19 (1988) 1687-1694 